\title{
HLA-DQB1 and HLA-DRB1 expression is associated with disease severity in IgAN
}

\author{
Xueyu Zhan ${ }^{1 \#}$, Fei Deng ${ }^{1 \#}$, Amanda Y. Wang ${ }^{2,3,4}$, Qin Chen ${ }^{1}$, Yongjing Du ${ }^{1}$, Qiuxia Wang ${ }^{1}$, Xiang Zhong ${ }^{1}$, \\ Ping Zhang ${ }^{1}$, Wei Wang ${ }^{1}$, Shasha Chen ${ }^{1}$, Guisen Li ${ }^{1}$, Li Wang ${ }^{1}$, Wei Wang ${ }^{1}$ \\ ${ }^{1}$ Renal Department and Nephrology Institute, Sichuan Provincial People's Hospital, School of Medicine, University of Electronic Science and \\ Technology of China, Chengdu, China; ${ }^{2}$ Renal and Metabolic Division, The George Institute for Global Health, University of NSW, Sydney, \\ Australia; ${ }^{3}$ Department of Renal Medicine, Concord Repatriation General Hospital, Concord, Australia; ${ }^{4}$ The Concord Clinical School, University \\ of Sydney, Sydney, Australia \\ Contributions: (I) Conception and design: X Zhan, F Deng, W Wang, AY Wang, G Li, L Wang; (II) Administrative support: W Wang; (III) Provision \\ of study materials or patients: X Zhan, F Deng; (IV) Collection and assembly of data: Q Chen, Y Du, Q Wang, P Zhang, W Wang; (V) Data analysis \\ and interpretation: S Chen, X Zhong; (VI) Manuscript writing: All authors; (VII) Final approval of manuscript: All authors. \\ \#The authors contributed equally to the work. \\ Correspondence to: Wei Wang, MD, PhD. Renal Department and Nephrology Institute, Sichuan Provincial People's Hospital, School of Medicine, \\ University of Electronic Science and Technology of China, Chengdu, China. Email: wangweisz@med.uestc.edu.cn; Amanda Y. Wang, MBBS, PhD. \\ Renal and Metabolic Division, The George Institute for Global Health, University of NSW, Sydney, Australia; Department of Renal Medicine, Concord \\ Repatriation General Hospital, Concord, Australia; The Concord Clinical School, University of Sydney, Australia. Email: awang@georgeinstitute.org.au.
}

Background Several genome-wide association studies have found that HLA class II histocompatibility antigen, DQ beta1 (HLA-DQB1) and HLA class II histocompatibility antigen, DR beta1 (HLA-DRB1) were associated with immunoglobulin A nephropathy (IgAN). However, few studies have explored the association between HLA-DQB1 and HLA-DRB1 expression and IgAN. This is the first study to investigate the relationship between HLA-DQB1 and HLA-DRB1 expression and clinical pathological characteristics.

Methods: A total of 113 patients with biopsy-proven IgAN and 71 healthy control patients participated in this study. HLA-DQB1 and HLA-DRB1 expression in peripheral blood lymphocytes was measured by quantitative reverse-transcription polymerase chain reaction (qRT-PCR) and flow cytometry. Serum galactose-deficient IgA1 (Gd-IgA1) level was measured by an enzyme-linked immunosorbent assay kit. The clinical and histopathological data of patients with IgAN were collected at the time of renal biopsy. Pearson's or Spearman's correlation coefficients were used to analyze the correlation between the expression of HLADQB1 and HLA-DRB1 mRNA and protein and the clinical pathological features of IgAN.

Results: HLA-DQB1 and HLA-DRB1 messenger ribonucleic acid expression was decreased in IgAN patients compared to healthy control patients $(\mathrm{P}<0.01)$. HLA-DQB1 and HLA-DRB1 protein expression was significantly lower in IgAN patients than healthy control patients $(\mathrm{P}<0.05)$. HLA-DQB1 and HLA-DRB1 protein expression was positively correlated with $24-\mathrm{h}$ urinary protein excretion $(\mathrm{P}<0.05)$. HLA-DRB1 protein expression was negatively correlated with renal function as measured by an estimated glomerular filtration rate $(\mathrm{P}<0.05)$. HLA-DRB1 protein expression was higher in patients with crescentic IgAN than patients without crescent formation $(\mathrm{P}<0.05)$.

Conclusions: Our study found the expression of HLA-DQB1, HLA-DRB1 were associated with the disease severity of IgAN and abnormal HLA-DQB1 and HLA-DRB1 expression may aggravate the progression of IgAN. We intend to gather further follow-up data to explore the effects of HLA-DQB1 and HLA-DRB1 expression on the prognosis of IgAN.

Keywords: IgA nephropathy; HLA class II histocompatibility antigen, DQ beta1 (HLA-DQB1); HLA class II histocompatibility antigen, DR beta1 (HLA-DRB1); gene expression; clinical parameters 
Submitted Jun 16, 2021. Accepted for publication Sep 02, 2021.

doi: 10.21037/apm-21-2065

View this article at: https://dx.doi.org/10.21037/apm-21-2065

\section{Introduction}

Since its first description in 1968 by Berger and Hinglais (1), immunoglobulin A nephropathy (IgAN) has become one of the most common primary glomerulonephritis and is a crucial cause of end-stage kidney disease worldwide (2). Accounting for $52.66 \%$ of all primary glomerulopathies, IgAN is a common condition in China (3-5).

The human leukocyte antigen (HLA)class II genes are located on the short arm of chromosome 6 . The gene II products encoding three main expression classes are divided into three main subregions: DP, DQ and DR (6).

Previous genome-wide association studies (GWASs) on IgAN have shown that the major histocompatibility complex (MHC) locus is correlated with disease risk. A study of IgAN in a European population demonstrated that the human leukocyte antigen (HLA) region contained the strongest risk alleles, of which the most powerful signals arose from the HLA class II histocompatibility antigen, DQ (HLA-DQ) locus (7). Yu et al. conducted a GWAS and identified several independently associated signals arising from the HLA region in a Chinese population (8). Further, a larger cohort revealed that there was a strong association between HLA class II histocompatibility antigen, DQ beta1 (HLA-DQB1) and HLA class II histocompatibility antigen, DR beta1 (HLA-DRB1) and IgAN, and that the DRB1*1501-DQB1*0602 haplotype had protective effects on IgAN (9). Recently, a GWAS of IgAN performed on individuals of European and East-Asian ancestry identified a new independent signal at HLA-DQB1 (10). In our previous study, we used PCR sequence-based typing (PCR-SBT) technique to detect the HLA-DQB1 alleles in patients with IgAN and found that the frequency of HLA-DQB $1 * 060101$ alleles was increased in IgAN patients, especially higher in patients with urine protein $\geq 1.0 \mathrm{~g} / 24 \mathrm{~h}$ (11). Jiyun et al. found that the frequency of HLA-DRB $1 * 04$ alleles was significantly increased in patients with IgAN (12).

HLA-II molecules are expressed on the surface of antigen-presenting cells (APCs), such as B cells, T cells, and monocytes, which present exogenous antigens through the formation of HLA-peptide combinations. HLApeptide combinations are specifically recognized by cluster of differentiation 4 positive $\left(\mathrm{CD}^{+} \mathrm{T}\right)$ cells through $\mathrm{T}$ cell receptors (TCRs). Numerous studies have shown that coding variations in the structure of HLA-II molecules and HLA-II gene expression levels affect autoreactive HLApeptide-TCR interactions, the downstream consequence of which is the activation of autoreactive effector T cells (13). Thus, aberrant HLA-DQB1 and HLA-DRB1 expression via the regulation of $\mathrm{CD}^{+} \mathrm{T}$ cell-dependent immune responses is important in the development of autoimmunity.

Despite numerous studies investigated the role of HLAII gene in IgAN, the association between the HLA-DQB1, HLA-DRB1 expression and IgAN remains unclear. The aim of this study was to examine the levels of HLA-DQB1, DRB1 messenger ribonucleic acid (mRNA) and protein expression in IgA nephropathy, as well as to investigate the relationships between the HLA-DQB1, DRB1 expression and clinical-pathological features of IgAN.

We present the following article in accordance with the STROBE reporting checklist (available at https://dx.doi. org/10.21037/apm-21-2065).

\section{Methods}

\section{Recruitment of IgAN and bealthy control patients}

Patients with biopsy-proven IgAN at Sichuan Provincial People's Hospital from June 2018 to December 2019 were recruited for this study. Patients with other primary and secondary glomerulonephritis diseases, such as HenochSchonlein purpura, lupus, and chronic hepatitis, were excluded. The healthy control patients (with no past medical history such as hypertension, diabetes, Systemic diseases, etc.) were recruited from the Health Management Center and Physical Examination Center. Peripheral blood samples of all participants were obtained. The clinical pathological data of the patients with IgAN were collected at the time of the renal biopsy.

Clinical factors, such as hypertension, massive proteinuria (sustained $24-\mathrm{h}$ urinary protein excretion $>1.0 \mathrm{~g} / 24 \mathrm{~h}$ ), decreased estimated glomerular filtration rate $\left(\mathrm{eGFR}<60 \mathrm{~mL} / \mathrm{min} / 1.73 \mathrm{~m}^{2}\right)$ at the time of renal biopsy (14), and severe pathological lesions are indicators of poor prognosis for IgA nephropathy (15). Therefore, pre-specified subgroup analyses were conducted based 
on the presence of pre-existing hypertension, amounts of proteinuria, renal function at baseline and MEST-C scores [mesangial hypercellularity $(M)$, endocapillary cellularity (E) lesions, segmental sclerosis (S), interstitial fibrosis/ tubular atrophy $(\mathrm{T})$ lesions and crescents pathological scores (C)] (15). Patients were divided into the following groups: the hypertensive group [defined as a systolic blood pressure $(\mathrm{SBP}) \geq 140 \mathrm{mmHg}$, a diastolic blood pressure (DBP) $\geq 90 \mathrm{mmHg}$, or a history of antihypertensive medication use] and the normotensive group; the high proteinuria group (defined as $24-\mathrm{h}$ urinary protein excretion $\geq 1.0 \mathrm{~g} / 24 \mathrm{~h}$ ) and the low proteinuria group (defined as $24-\mathrm{h}$ urinary protein excretion $<1.0 \mathrm{~g} / 24 \mathrm{~h}$ ); the high estimated glomerular filtration rate (eGFR) level group (defined as an eGFR $>60 \mathrm{~mL} / \mathrm{min} / 1.73 \mathrm{~m}^{2}$ ) and the low eGFR level group (defined as an eGFR $\leq 60 \mathrm{~mL} / \mathrm{min} / 1.73 \mathrm{~m}^{2}$ ); the $M 0$ group (defined as a mesangial score $<0.5$ ) and the $M 1$ group (defined as a mesangial score $>0.5$ ); the E0 group (defined as endocapillary hypercellularity absent) and the E1 group (defined as endocapillary hypercellularity present); the S0 group (defined as segmental glomerulosclerosis absent) and the $\mathrm{S} 1$ group (defined as segmental glomerulosclerosis present); the T0 group (defined as tubular atrophy/ interstitial fibrosis $\leq 25 \%$ ), the $\mathrm{T} 1$ group (defined as $26 \% \leq$ tubular atrophy/interstitial fibrosis $\leq 50 \%$ ) and the T2 group (defined as tubular atrophy/interstitial fibrosis $>50 \%$ ); and the C0 group (defined as cellular/fibro-cellular crescents absent), the $\mathrm{C} 1$ group (defined as cellular/fibrocellular crescents present in at least 1 glomerulus and $<25 \%$ ) and the C2 group (defined as cellular/fibro-cellular crescents $>25 \%$ ).

The study protocol was reviewed and approved by the Ethical Committee of Sichuan Provincial People's Hospital. All the participants provided informed consent prior to data collection. All procedures performed in this study involving human participants were in accordance with the Declaration of Helsinki (as revised in 2013).

\section{Serum Gd-IgA1 levels}

The serum Gd-IgA1 levels of all participants were detected using a novel lectin-independent enzymelinked immunosorbent assay (ELISA) kit with the $\mathrm{N}$-acetylgalactosamine-specific monoclonal antibody KM55 (IBL, Japan). Serum samples were diluted 400-fold. The diluted serum Gd-IgA1 levels were then measured in accordance with the manufacturer's guidelines (16).

\section{The measurement of HLA-DQB1 and HLA-DRB1 mRNA in PBLs}

The expression of HLA-DQB1 and HLA-DRB1 mRNA on peripheral blood lymphocytes (PBLs) was measured by quantitative reverse-transcription polymerase chain reaction (qRT-PCR). PBLs in patients with IgAN and healthy control patients were extracted by Ficoll-Hypaque solution. The total RNA of PBLs was then isolated using an RNA isolation reagent (Invitrogen, USA) in accordance with the manufacturer's guidelines. Next, the total RNA was transcribed into complementary deoxyribonucleic acids (cDNAs) using RT II reverse transcriptase. cDNAs were used as a PCR template for HLA-DQB1 and HLA-DRB1 gene-specific primers. The amplification reactions were determined by the CFX96 Real-Time PCR system (Bio-RAD, USA). The gene-specific primers of HLA-DQB1, HLA-DRB1, and GAPDH (used as an internal control) were as follows: GAPDH forward 5'-GGAGCGAGATCCCTCCAAAAT-3', reverse 5'-GGCTGTTGTCATACTTCTCATGG-3'; HLADQB1 forward 5'-TGGAGTGGCGGGCTCAG-3', reverse 5'-CAGGAGTCAGTGCAGAAGCC-3'; HLADRB1 forward 5'-TCCTGTGGCAGCCTAAGAG-3', reverse 5'-GCACGGACTCCTCCTGATTAT-3'.

Finally, data were collected and quantitatively analyzed using the $2^{-\Delta \Delta C t}$ method.

\section{The measurement of HLA-DQB1 and HLA-DRB1 protein expressed on APCs}

To determine the HLA-DQB1 and HLA-DRB1 protein expressed on the leukocyte surface, flow cytometry (BD, USA) was performed on the collected peripheral blood. Antibodies against HLA-DQB1-Fluorescein Isothiocyanate (eBioscience, USA), HLA-DRB1-Phycoerythrin (BD, USA), CD19 Peridinium Chlorophyll Protein-Cyanidin5.5 (BD, USA), CD3-Allophycocyanin (BD, USA), and CD56Phycoerythrin - Cyanidin 7 (BD, USA) were used in accordance with the manufacturers' guidelines. After 2030 minutes of incubation without light at room temperature, 1× FACS (Fluorescence activated Cell Sorting) lysing solution was diluted 10 times and added into each tube to lyse the red blood cells. The samples were then centrifuged at $1,500 \mathrm{r} / \mathrm{min}$ for 5 minutes at room temperature, and the upper layer was discarded then tested. The mean fluorescence intensities of HLA-DQB1 and HLA-DRB1 protein expressed on all nucleated cells, total lymphocytes, 
B cells, T cells, natural killer (NK) cells, monocytes, and granulocytes were reported.

The gating strategy used to detect the expression of HLA-DQB1 and HLA-DRB1 protein on leukocytes were shown in Figure 1.

\section{Statistical analysis}

Quantitative variables with normal distribution are expressed as the mean \pm standard deviation $(\mathrm{SD})$, and medians with interquartile ranges (IQRs) are used for variables with a non-normal distribution. Categorical data are represented as $\mathrm{n} \%$. Variables with normal distribution were analyzed using Student's ( $T$ ) tests. Variables with nonnormal distribution were compared using either KruskalWallis tests or Mann-Whitney U tests. Pearson's or Spearman's correlation coefficients were used to analyze the correlation between the expression of HLA-DQB1 and HLA-DRB 1 mRNA and protein and the clinical pathological features of IgAN.

All analyses were performed using SPSS, version 22.0.0.0 (IMB Corp., New York, USA). A $\mathrm{P}<0.05$ was considered statistically significant.

\section{Results}

\section{Baseline characteristics}

A total of 113 IgAN patients and 71 healthy control patients were recruited to participate in this study. The 113 enrolled IgAN patients had a mean age of $38.3 \pm 14.4$ years old, and $54(47.8 \%)$ patients were male. The 71 healthy control patients had a mean age of $38.6 \pm 11.8$ years, and $34(47.9 \%)$ were male. There was no difference in age and sex between the IgAN patients and control patients. The baseline characteristics and the scores of the Oxford classifications of IgAN patients are set out in Table 1 .

\section{Serum Gd-IgA1 levels}

Compared to the healthy control patients, the GdIgA1 levels in IgAN patients were significantly increased $(\mathrm{P}<0.0001$; see Figure 2).

\section{Expression of HLA-DQB1 and HLA-DRB1 $m R N A$}

HLA-DQB1 and HLA-DRB1 mRNA expression of PBLs in the $86 \mathrm{IgAN}$ patients and the 32 healthy control patients was measured by qRT-PCR. The expression of HLA-DQB1 $(\mathrm{P}<0.01)$ and HLA-DRB1 mRNA $(\mathrm{P}<0.01)$ was significantly lower in IgAN patients than in healthy control patients (see Figure 3).

\section{Expression of $H L A-D Q B 1$ and $H L A-D R B 1$ protein}

HLA-DQB1 and HLA-DRB1 protein expression was tested in 47 IgAN patients and 39 healthy control patients. The representative comparison of HLA-DQB1 and HLA-DRB1 protein expression in patients with IgAN and healthy control patients was shown in Figure 4. The HLA-DQB1 protein on nucleated cells $(\mathrm{P}=0.04)$, B cells $(\mathrm{P}<0.01)$, NK cells $(\mathrm{P}<0.001)$, and granulocytes $(\mathrm{P}=0.01)$ were significantly more decreased in IgAN patients than healthy control patients (see Figure $5 A$ and Table S1). Compared to the healthy control patients, the HLA-DRB1 protein expression on NK cells $(\mathrm{P}<0.01)$ was significantly decreased and the HLA-DRB1 protein expression on granulocytes was increased in IgAN patients $(\mathrm{P}<0.001$; see Figure $5 B$ and Table $\mathrm{S} 2)$.

\section{Correlation between HLA-DQB1 and HLA-DRB1 mRNA expression and clinical pathological characteristics in IgAN patients}

A negative correlation was observed between HLA-DQB1 mRNA expression and white blood cell (WBC) counts ( $\mathrm{r}=$ $-0.24, \mathrm{P}=0.03$; see Table S3). There was no difference in HLA-DQB1 and HLA-DRB1 mRNA expression between the high and low proteinuria groups, hypertensive and normotensives groups, high and low eGFR groups, and different pathological lesion groups (see Table S4).

Correlation between $H L A-D Q B 1$ and $H L A-D R B 1$ protein expression and clinical pathological characteristics in IgAN patients

HLA-DQB1 protein expression on lymphocytes was positively correlated with serum Gd-IgA1 levels $(\mathrm{r}=0.33$, $\mathrm{P}=0.03$; see Table 2). HLA-DQB1 protein on NK cells ( $\mathrm{r}=0.31$, $\mathrm{P}=0.04)$ and granulocytes $(\mathrm{r}=0.30, \mathrm{P}=0.04)$ was positively correlated with 24-h urinary protein excretion (see Table 2). HLA-DRB1 protein expression on NK cells was positively correlated to $24-\mathrm{h}$ urinary protein excretion $(\mathrm{r}=0.30, \mathrm{P}=0.04)$, and HLA-DRB1 protein expression on $T$ cells was negatively correlated with eGFR ( $\mathrm{r}=-0.36, \mathrm{P}=0.01$; see Table 3$)$.

Further, a subgroup analysis based on clinical stratification showed that HLA-DQB1 protein expression 
A

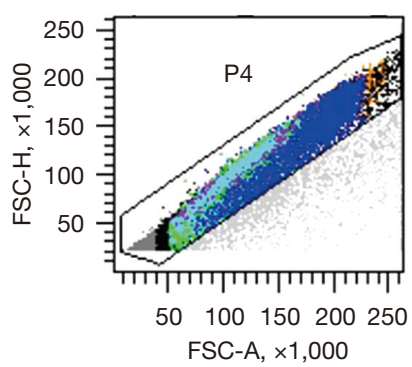

C

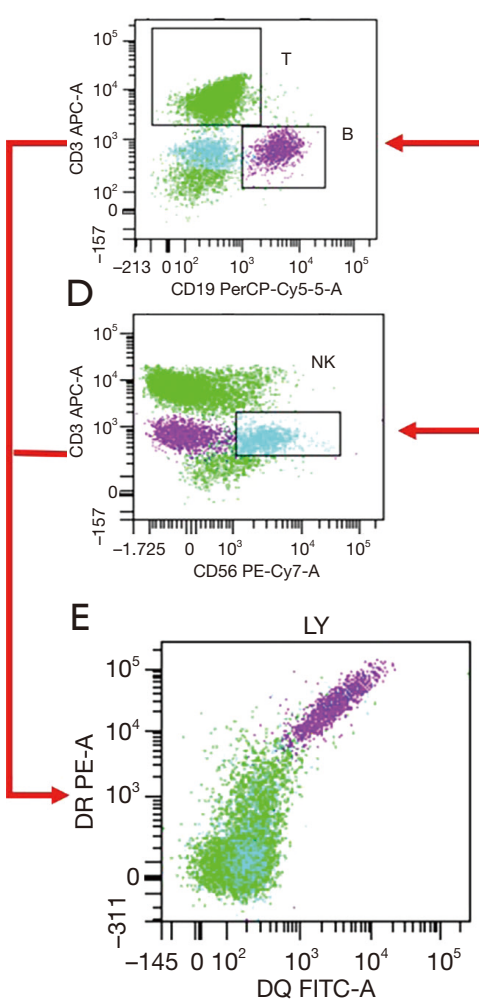

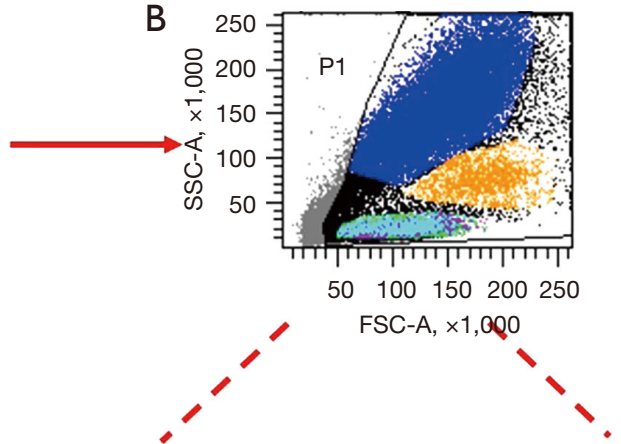

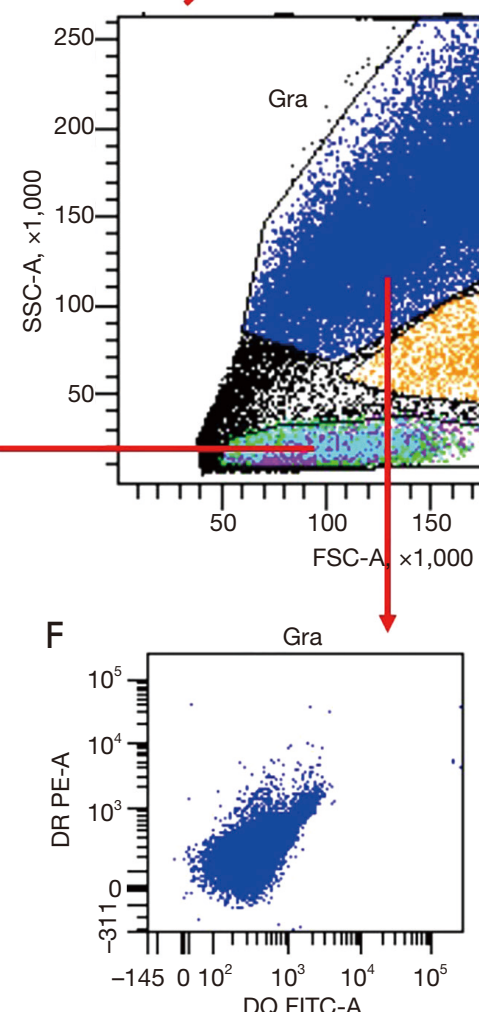

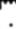

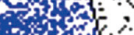

(a)

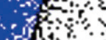

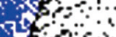
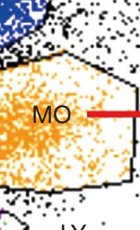
LY 200

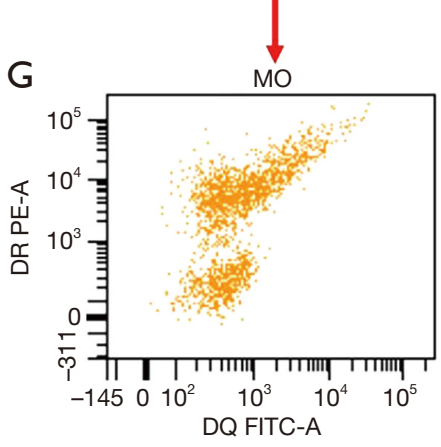

Figure 1 Gating strategy for the determination of MFI of HLA-DQB1, HLA-DRB1 protein expression on all nucleated cells, lymphocytes, $\mathrm{T}$ cells, B cell, NK cells, monocytes and granulocytes. The figure shown is a representative analysis. Samples were analyzed using the following gating strategy: (A) exclusion of sticky cells and gate nucleated cells (FSC-H vs. FSC-A); (B) Gate for the lymphocytes, monocytes and granulocytes based on the size and complexity of the event (SSC-A vs. FSC-A); (C) T cell and B cell gating (CD3 APC-A vs. CD19PerCP-Cy5-5-A); (D) NK cell gating (CD3 APC-A vs. CD56 PE-Cy7-A); (E) HLA-DQB1, HLA-DRB1 protein expression on lymphocytes including T cells, B cells and NK cells (DQ-FITC-A vs. DR-PE-A); (F) HLA-DQB1, HLA-DRB1 protein expression on granulocytes (DQ-FITC-A vs. DR-PE-A); (G) HLA-DQB1, HLA-DRB1 protein expression on monocytes (DQ-FITC-A vs. DRPE-A). Ly, lymphocytes; T, T cells; B, B cells; NK, natural killer cells; Gra, granulocytes; MO, monocytes; FSC-H, forward scatter height; FSC-A, forward scatter area; SSC-A, side scatter area; CD3 APC-A, CD3 Allophycocyanin area; CD19PerCP-Cy5-5, CD19 Peridinium Chlorophyll Protein-Cyanidin5.5; CD56 PE-Cy7-A, CD56-Phycoerythrin - Cyanidin 7 area; DQ-FITC-A, DQB1-Fluorescein Isothiocyanate area; DR-PE-A, DRB1-Phycoerythrin area; MFI, mean fluorescence intensity. 
Table 1 Baseline characteristics of IgAN patients and healthy patients.

\begin{tabular}{|c|c|c|c|}
\hline & $\lg A N$ & Healthy & $\mathrm{P}$ \\
\hline Male, n (\%) & $54(47.8)$ & $34(47.9)$ & 0.99 \\
\hline Age (years) & $38.3 \pm 14.4$ & $38.6 \pm 11.8$ & 0.88 \\
\hline $\mathrm{BMI}\left(\mathrm{kg} / \mathrm{m}^{2}\right)$ & $23.6 \pm 3.5$ & $22.8 \pm 3.1$ & 0.10 \\
\hline $\mathrm{DBP}(\mathrm{mmHg})$ & $84.2 \pm 13.9$ & $72.3 \pm 10.4$ & $4.83 \times 10^{-9}$ \\
\hline $\mathrm{SCr}(\mu \mathrm{mol} / \mathrm{L})$ & $111.6 \pm 70.1$ & $64.6 \pm 13.3$ & $2.02 \times 10^{-10}$ \\
\hline eGFR $\left(\mathrm{mL} / \mathrm{min} / 1.73 \mathrm{~m}^{2}\right)$ & $79.7 \pm 33.6$ & $112.2 \pm 11.5$ & $6.47 \times 10^{-17}$ \\
\hline $\mathrm{UA}(\mu \mathrm{mol} / \mathrm{L})$ & $399.1 \pm 112.0$ & $313.4 \pm 68.5$ & $1.11 \times 10^{-9}$ \\
\hline $\mathrm{Hb}(\mathrm{g} / \mathrm{L})$ & $130.0 \pm 20.9$ & $144.3 \pm 14.5$ & $1.50 \times 10^{-7}$ \\
\hline WBC $\left(10^{9} / \mathrm{L}\right)$ & $6.7(5.7,8.1)$ & $5.51(4.9,6.3)$ & $1.21 \times 10^{-7}$ \\
\hline TC (mmol/L) & $4.6(4.1,5.5)$ & $4.3(4.0,5.0)$ & $4.00 \times 10^{-3}$ \\
\hline $\mathrm{TG}(\mathrm{mmol} / \mathrm{L})$ & $1.6(1.2,2.5)$ & $1.0(0.7,1.4)$ & $2.08 \times 10^{-10}$ \\
\hline HDL-C (mmol/L) & $1.3(1.0,1.5)$ & $1.4(1.2,1.5)$ & 0.02 \\
\hline LDL-C (mmol/L) & $2.7(2.2,3.3)$ & $2.3(2.0,3.1)$ & 0.01 \\
\hline Serum $\lg A(g / L)$ & $2.9(2.2,3.6)$ & - & \\
\hline \multicolumn{4}{|c|}{ Oxford classification, n (\%) } \\
\hline
\end{tabular}

IgAN, IgA nephropathy; BMI, body mass index; SBP, systolic blood pressure; DBP, diastolic blood pressure; SCr, serum creatinine; eGFR, estimated glomerular filtration rate; UA, uric acid; ALB, serum albumin; Hb, hemoglobin; WBC, white blood cells; TG, triglyceride; TC, total cholesterol; HDL-C; high density lipoprotein cholesterol; LDL-C, low density lipoprotein cholesterol; M, mesangial cell proliferation; E, endothelial cell proliferation; S, glomerular segmental sclerosis; T, tubular atrophy, interstitial fibrosis; C, crescentic lesions.

on granulocytes $(\mathrm{P}<0.01)$ and HLA-DRB 1 protein expression on NK cells $(\mathrm{P}=0.02)$ were more increased in patients with high urinary protein excretion than patients with low urinary protein excretion (see Table S5). No difference in HLA-DQB 1 and HLA-DRB 1 protein expression between the hypertensive and normotensive groups and between the low and high eGFR groups was observed (see Tables S6,S7).

Finally, the differential expression of HLA-DQB1 and HLA-DRB1 in different pathological groups was analyzed
(Tables S8-S11). As results showed, both HLA-DQB1 and HLA-DRB1 protein expression on granulocytes were higher in the $\mathrm{S} 1$ group than the $\mathrm{S} 0$ group $(\mathrm{P}=0.04 ; \mathrm{P}=0.01$; see Table S10). Further, HLA-DRB1 protein expression on $\mathrm{T}$ cells and $\mathrm{NK}$ cells was increased in the C1-2 group compared to the $\mathrm{C} 0$ group $(\mathrm{P}=0.02 ; \mathrm{P}<0.01$; see Table $\mathrm{S} 11)$.

\section{Discussion}

Our study found that HLA-DQB1 and HLA-DRB1 


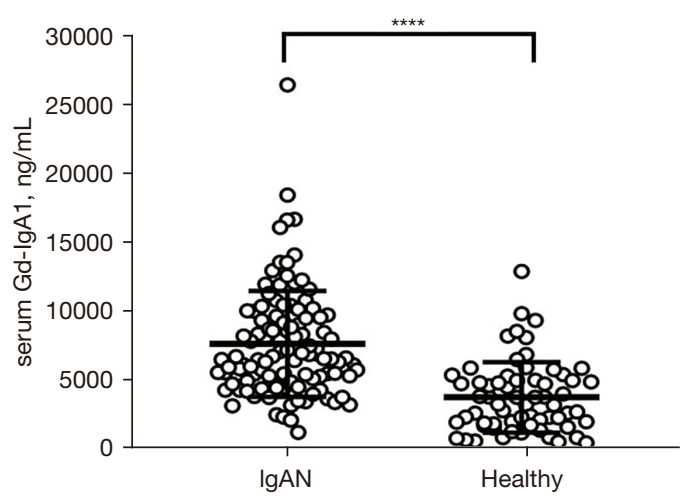

Figure 2 The serum Gd-IgA1 level in 113 IgAN patients and 71 healthy control patients. The circle represents the individual patients. The black lines indicate the mean and SD, respectively. ${ }^{* * * *} \mathrm{P}<0.0001$. IgAN, immunoglobulin A nephropathy; GdIgA1, galactose-defected IgA1; SD, standard deviation.

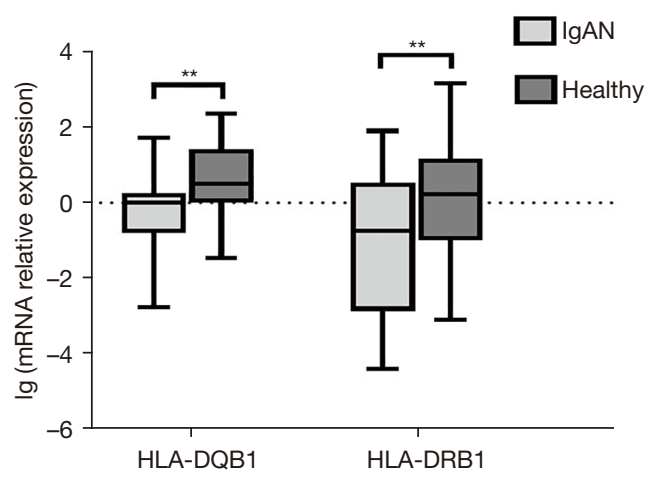

Figure 3 HLA-DQB1 and HLA-DRB1 mRNA expression of peripheral blood mononuclear cells in 86 IgAN patients and 32 healthy control patients. The level of mRNA expression is calculated as 19 (HLA-DQB1 or HLA-DRB1 mRNA relative expression). ${ }^{* *} \mathrm{P}<0.01$. IgAN, immunoglobulin A nephropathy; HLA-DQB1, histocompatibility antigen, DQ beta1; HLA-DRB1, histocompatibility antigen, DR beta1.

expression was downregulated on the PBLs of IgAN patients. The expression of HLA-DQB1 protein was positively correlated with 24-h urinary protein excretion and serum Gd-IgA1; the expression of HLA-DRB1 protein was positively correlated with 24-h urinary protein excretion and negatively correlated with eGFR. Differential HLA-DQB1 and HLA-DRB1 protein expression in different pathological groups was also observed. Notably, patients with crescentic lesions had higher HLA-DRB1 protein expression than patients without crescent formation. The above data indicate that the abnormal expression of HLA-DQB1 and HLA$\mathrm{DRB} 1$ is possible involved in the pathogenesis of IgAN and may aggravate the progression of IgAN.

We also found that the expression of HLA-DQB1 and HLA-DRB1 mRNA was more decreased in IgAN patients than healthy control patients. The mechanism by which this occurs remains unknown. Numerous studies had shown that HLA-DQB1 and HLA-DRB1 mRNA is abnormally expressed in autoimmune diseases, such as lupus and type1 diabetes, and that such expression might be related to DNA methylation (17-19). Thus, we hypothesized that the reduction of HLA-DQB1 and HLA-DRB1 mRNA expression in IgAN may also be related to DNA methylation. In the future, we will investigate the methylation levels of HLA-DQB1 and HLA-DRB1 genes in IgAN patients and explore their mechanism in IgAN further.

Our study also showed that the HLA-DQB1 protein expressed on nucleated cells, B cells, NK cells, and granulocytes, and the HLA-DRB1 protein expressed on NK cells were decreased in IgAN patients compared to control patients. It has been reported that the downregulation of HLA expression can lead to an imbalance in protection against infection (20). Research has shown that the HLADQB1 expression of monocytes was decreased in patients with cystic fibrosis and the downregulation of HLA-DQB1 expression might lead to a defect in immune defense, which in turn might increase inflammation in the lungs (21). Thus, like other diseases, the downregulation of HLA-DQB1 and HLA-DRB1 protein expression in our study might also increase inflammation in nephrons.

Previous studies suggest that IgAN is an autoimmune disease with abnormally increased serum galactose-defected IgA1(Gd-IgA1) in most patients with IgAN (22). The widely accepted 'multi-hit' hypothesis, which is proposed to explain the pathogenesis involved in IgAN, consider the increased serum Gd-IgA1 as 'hit 1', initiating factors of $\operatorname{IgAN}$ and a serological indicator of poor prognosis (23). In our study, we found the expression of HLA-DQB1 protein on lymphocytes was positively correlated with serum Gd-IgA1.

Further, a correlation analysis also showed that the HLADQB1 protein expressed on NK cells and granulocytes, and the HLA-DRB1 protein expressed on NK cells were positively correlated with 24-h urinary protein excretion; the HLA-DRB1 protein on T cells was negatively associated with eGFR levels. Additionally, a further stratification analysis also indicated that HLA-DQB1 protein expression on granulocytes and HLA-DRB1 protein expression on NK cells were higher in the high proteinuria group than 

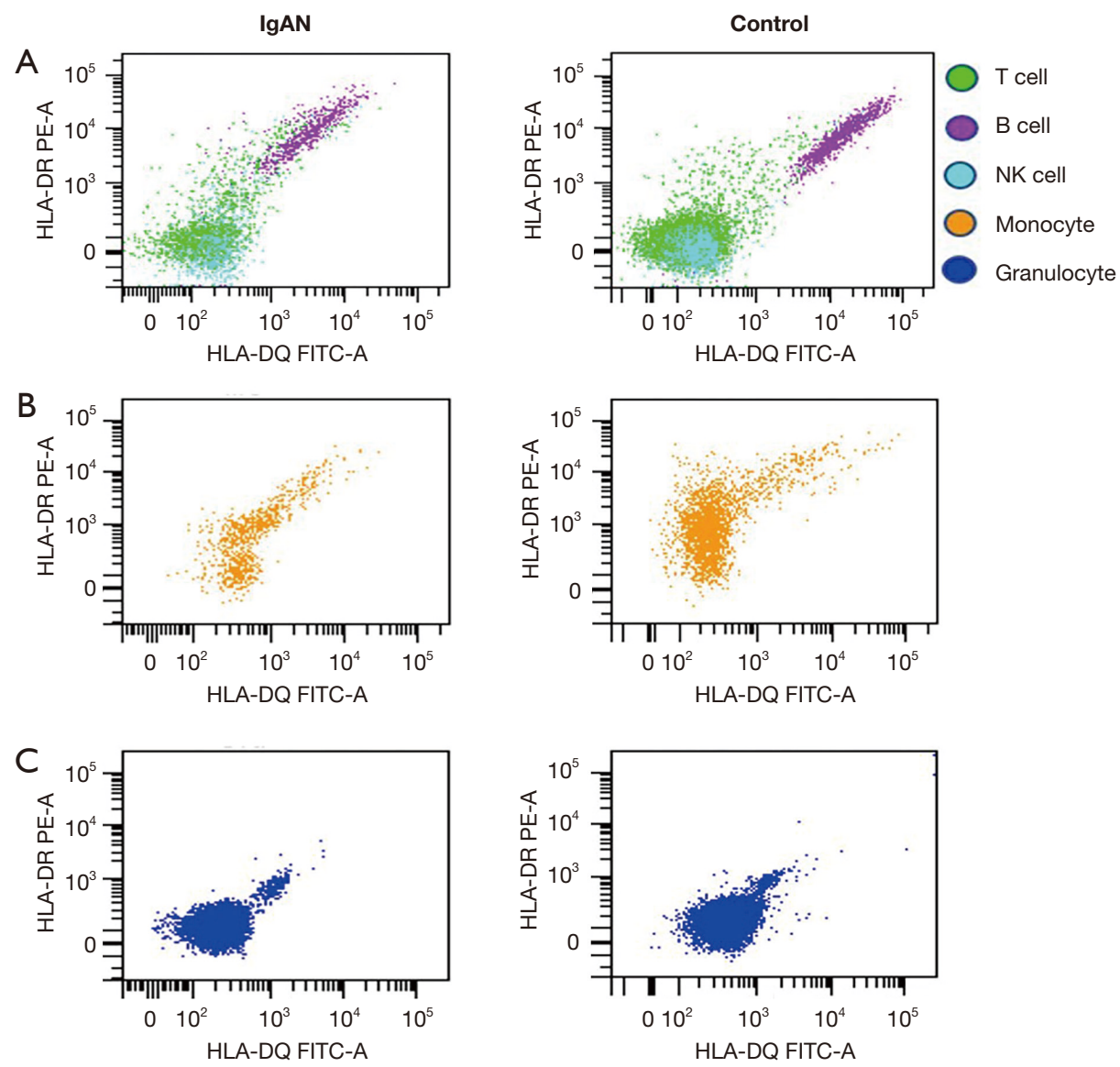

Figure 4 The expression of HLA-DQB1, HLA-DRB1 protein in patients with IgAN and healthy controls. (A) The expression of HLADQB1, HLA-DRB1 protein on lymphocytes including T cells, B cells and NK cells; (B) the expression of HLA-DQB1, HLA-DRB1 protein on monocytes; (C) the expression of HLA-DQB1, HLA-DRB1 protein on granulocytes. The green circles represent T cells, the pink circles represent B cells, the light blue circles represent NK cells, the orange circles represent monocytes, and the dark blue circles represent granulocytes. HLA-DR PE-A, HLA class II histocompatibility antigen, DRB1-phycoerythrin area; HLA-DQ FITC-A, HLA class II histocompatibility antigen, DQB1-fluorescein Isothiocyanate area; NK, natural killer; HLA-DQB1, histocompatibility antigen, DQ beta1; HLA-DRB1, histocompatibility antigen, DR beta1; IgAN, immunoglobulin A nephropathy.

the low proteinuria. These findings indicate that abnormal HLA-DQB1 and HLA-DRB1 expression was significantly correlated with the severity of IgAN.

In severe glomerular diseases, the HLA-II antigen molecule is upregulated in intrinsic renal cells, such as mesangial cells, tubular epithelial cells, endothelial cells, and podocytes (6). Previous studies have shown that the high expression of HLA-II antigens on podocytes might affect their function $(24,25)$. These studies indicated that the upregulation of the HLA-II gene plays an important role in the glomerular immune response. An abnormal immune response could induce renal inflammatory injury, which could affect the structure and function of the glomerular filtration barrier, increasing the glomerular permeability of macromolecules, which in turn increases the filtration of plasma proteins (26). An in-vitro study demonstrated that a $\mathrm{CD}^{+} \mathrm{T}$ cell-dependent immune response in the glomerulus injury could be caused by circulating MHC-II+ monocytes presenting intravascular antigens to $\mathrm{CD}^{+} \mathrm{T}$ cells $(27)$. According to the findings in our study, it appears that the upregulation of the HLA-DQB1 and HLA-DRB1 molecules expressed on circulating immune cells in IgAN patients might result in the dysregulation of $\mathrm{CD} 4+\mathrm{T}$ cell-dependent immune responses in glomerular, which in turn could induce the infiltration of inflammation in nephrons, leading to increased urinary protein excretion and a decline in eGFR. 


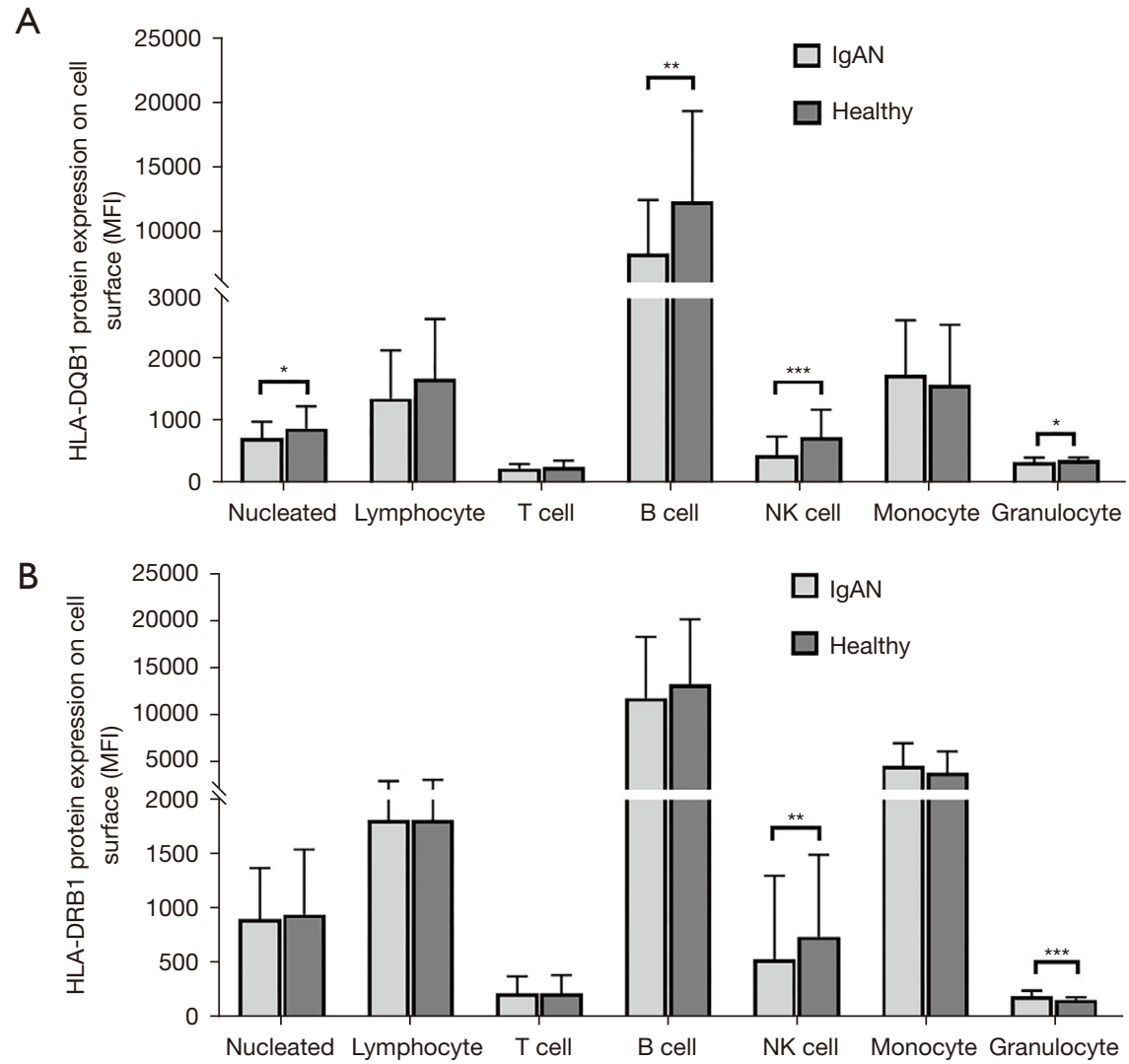

Figure 5 HLA-DQB1 and HLA-DRB1 protein expression in 47 IgAN patients and 39 healthy control patients. (A) The levels of HLADQB1 protein expressed on nucleated cells, lymphocytes, T cells, B cells, NK cells, monocytes, and granulocytes; (B) the levels of HLADRB1 protein expressed on nucleated cells, lymphocytes, T cells, B cells, NK cells, monocytes, and granulocytes. The expression of HLADQB1 and HLA-DRB1 protein on cell surface was calculated as MFI. ${ }^{*} \mathrm{P}<0.05 ;{ }^{* *} \mathrm{P}<0.01 ;{ }^{* *} \mathrm{P}<0.001$. HLA-DQB1, histocompatibility antigen, DQ beta1; NK, natural killer; IgAN, immunoglobulin A nephropathy; HLA-DRB1, histocompatibility antigen, DR beta1; MFI, mean fluorescence intensity.

Table 2 Correlation between HLA-DQB1 protein and clinical characteristics in 47 IgAN patients

\begin{tabular}{|c|c|c|c|c|c|c|c|}
\hline & Nucleated cell & Lymphocyte & T cell & B cell & NK cell & Monocyte & Granulocyte \\
\hline \multicolumn{8}{|c|}{ Gd-lgA1 (ng/mL) } \\
\hline$r$ & 0.18 & 0.33 & 0.09 & 0.10 & 0.11 & -0.12 & 0.08 \\
\hline \multicolumn{8}{|c|}{$\mathrm{SBP}(\mathrm{mmHg})$} \\
\hline$r$ & 0.13 & 0.18 & 0.16 & 0.23 & 0.08 & -0.01 & -0.03 \\
\hline \multicolumn{8}{|c|}{$\mathrm{DBP}(\mathrm{mmHg})$} \\
\hline$r$ & 0.09 & 0.09 & 0.14 & 0.26 & 0.11 & 0.01 & 0.02 \\
\hline $\mathrm{P}$ & 0.54 & 0.57 & 0.36 & 0.08 & 0.46 & 0.97 & 0.92 \\
\hline \multicolumn{8}{|c|}{ BMI $\left(k g / m^{2}\right)$} \\
\hline$r$ & 0.24 & 0.20 & 0.08 & 0.16 & 0.11 & 0.03 & 0.16 \\
\hline
\end{tabular}

Table 2 (continued) 
Table 2 (continued)

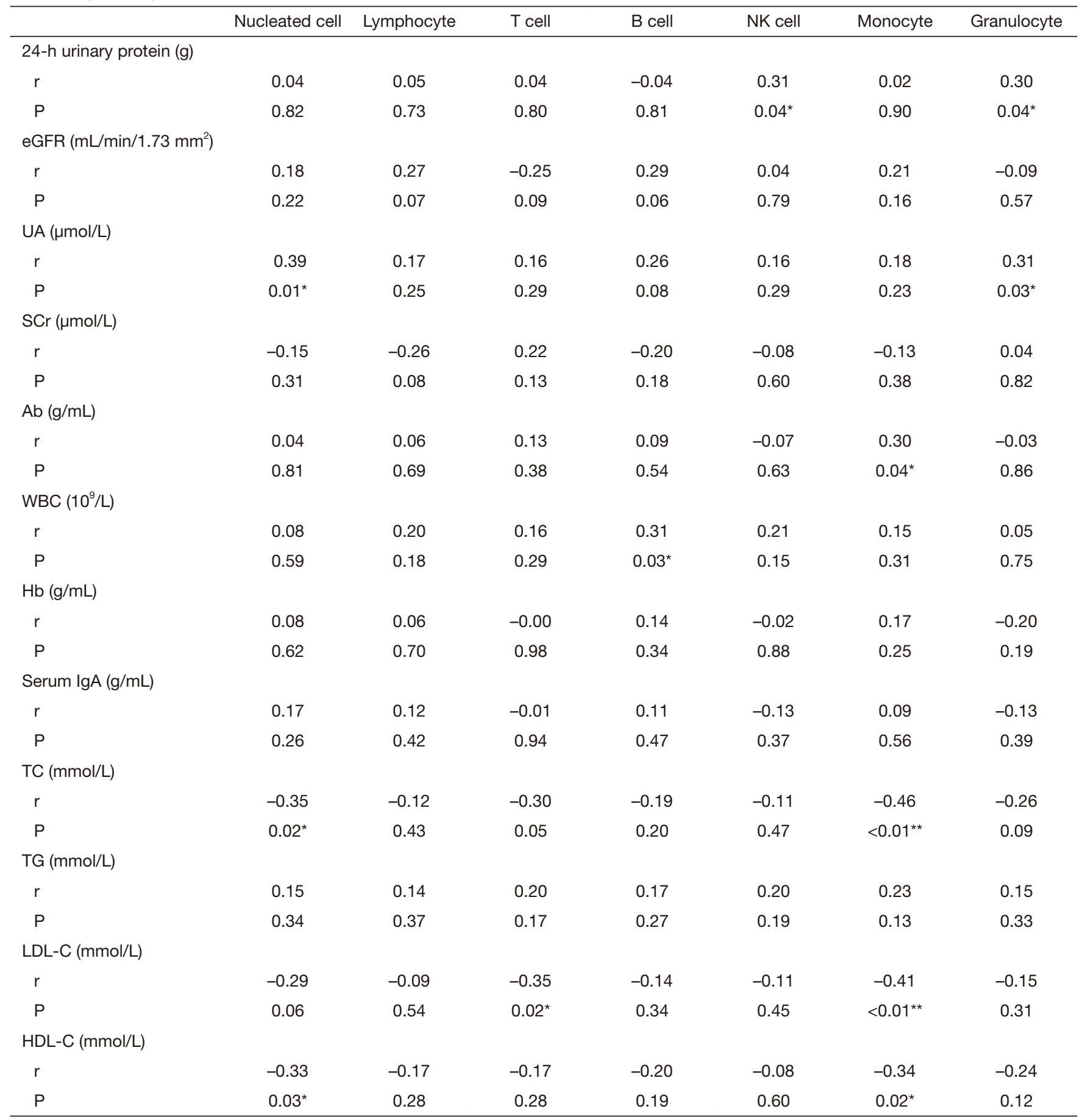

${ }^{*} \mathrm{P}<0.05 ;{ }^{*} \mathrm{P}<0.01$. HLA-DQB1, histocompatibility antigen, DQ beta1; IgAN, immunoglobulin A nephropathy; NK, natural killer; Gd-lgA1, galactose-deficient IgA1; SBP, systolic blood pressure; DBP, diastolic blood pressure; BMI, body mass index; 24-h urinary protein, 24 hour urinary protein; eGFR, estimated glomerular filtration rate; UA, uric acid; SCr, serum creatinine; Ab, serum albumin; WBC, white blood cells; Hb, hemoglobin; TC, total cholesterol; TG, triglyceride; LDL-C, low density lipoprotein cholesterol; HDL-C; high density lipoprotein cholesterol. 
Table 3 Correlation between HLA-DRB1 protein and clinical characteristics in $47 \mathrm{IgAN}$ patients

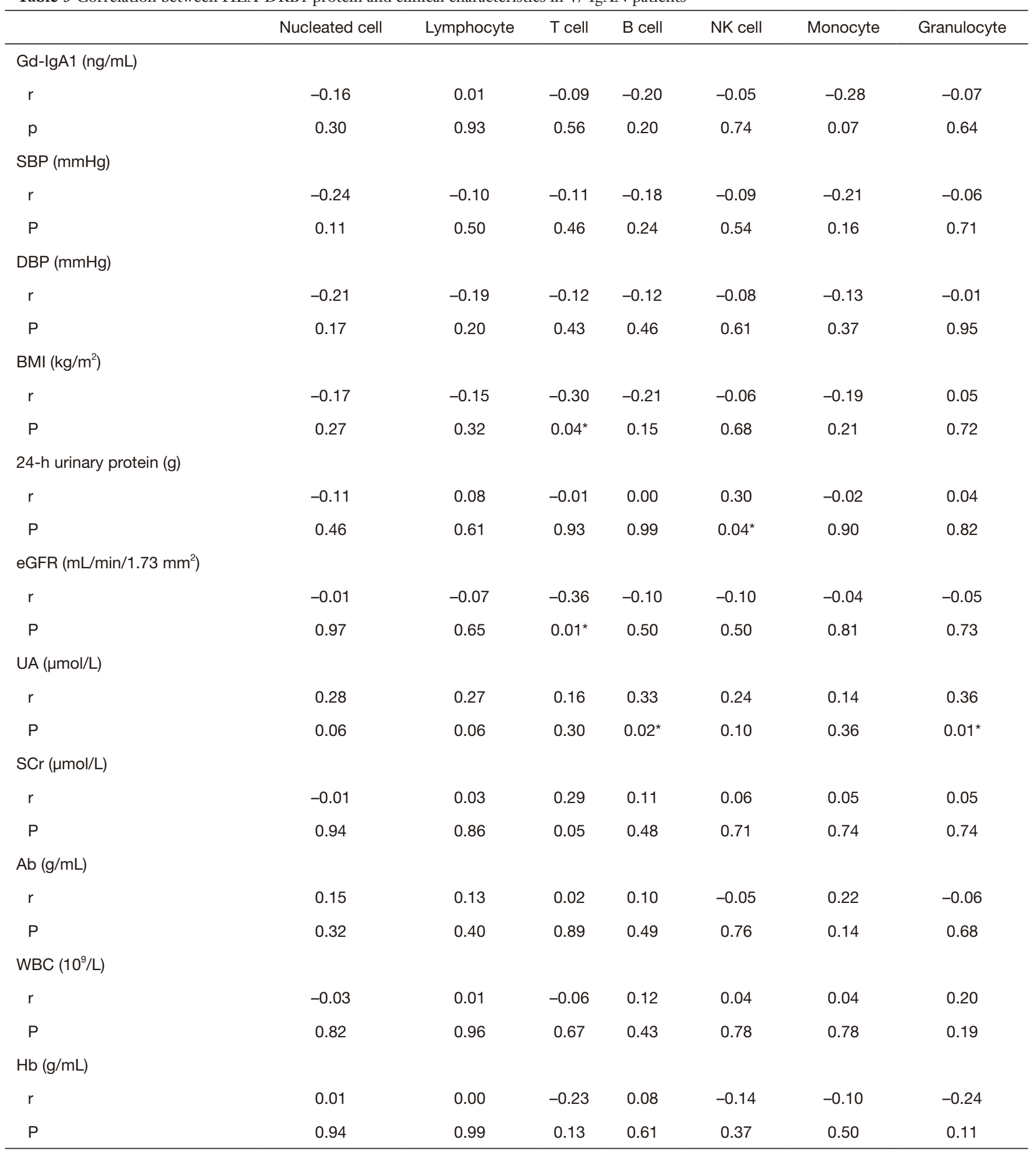

Table 3 (continued) 
Table 3 (continued)

\begin{tabular}{|c|c|c|c|c|c|c|c|}
\hline & Nucleated cell & Lymphocyte & T cell & B cell & NK cell & Monocyte & Granulocyte \\
\hline$r$ & 0.23 & 0.06 & 0.06 & 0.10 & -0.06 & 0.14 & 0.15 \\
\hline$P$ & 0.12 & 0.70 & 0.70 & 0.51 & 0.69 & 0.37 & 0.33 \\
\hline \multicolumn{8}{|c|}{ TC (mmol/L) } \\
\hline$P$ & $0.03^{*}$ & 0.18 & 0.62 & 0.32 & 0.54 & 0.05 & 0.11 \\
\hline \multicolumn{8}{|c|}{$\mathrm{TG}(\mathrm{mmol} / \mathrm{L})$} \\
\hline r & -0.05 & -0.05 & -0.11 & 0.02 & 0.12 & 0.06 & 0.15 \\
\hline $\mathrm{P}$ & 0.74 & 0.72 & 0.46 & 0.92 & 0.42 & 0.67 & 0.33 \\
\hline \multicolumn{8}{|c|}{ LDL-C (mmol/L) } \\
\hline$P$ & 0.26 & 0.78 & 0.88 & 0.86 & 0.92 & 0.24 & 0.17 \\
\hline \multicolumn{8}{|c|}{ HDL-C (mmol/L) } \\
\hline r & -0.21 & -0.15 & 0.01 & -0.10 & -0.12 & -0.23 & -0.22 \\
\hline $\mathrm{P}$ & 0.16 & 0.33 & 0.94 & 0.52 & 0.44 & 0.14 & 0.14 \\
\hline
\end{tabular}

${ }^{*} \mathrm{P}<0.05$. HLA-DQB1, histocompatibility antigen, DQ beta1; IgAN, immunoglobulin A nephropathy; NK, natural killer; Gd-lgA1, galactosedeficient IgA1; SBP, systolic blood pressure; DBP, diastolic blood pressure; BMI, body mass index; 24-h urinary protein, 24 hour urinary protein; eGFR, estimated glomerular filtration rate; UA, uric acid; SCr, serum creatinine; Ab, serum albumin; WBC, white blood cells; Hb, hemoglobin; TC, total cholesterol; TG, triglyceride; LDL-C, low density lipoprotein cholesterol; HDL-C; high density lipoprotein cholesterol.

Our analysis of the pathological data showed that the HLA-DQB1 and HLA-DRB1 protein levels were different in different pathological groups. Notably, HLA-DRB1 protein on $\mathrm{T}$ cells and NK cells was increased in patients with crescentic lesions than those without crescentic lesions. The interaction between HLA-peptide combinations and antigen-specific $\mathrm{CD}^{+} \mathrm{T}$ cells can determine effective $\mathrm{T}$ cell immunity, and abnormal cell immunity can induce injury in the kidneys $(13,28)$. Different CD4+ effector $\mathrm{T}$ cells have different effects on cell-mediated crescentic glomerulonephritis (GN). Basic research has shown that T-helper 1 effector CD4+ cells and T-helper 17 effector CD4+ cells participate in the development and progression of necrotizing/crescentic GN (29-32), while regulatory T cells are crucial in the resolution of crescentic GN $(33,34)$. Our results suggest that the abnormal expression of the HLA-II gene might lead to the formation of crescents by affecting the immunity of $\mathrm{CD} 4^{+}$effector $\mathrm{T}$ cells.

To our knowledge, this is the first study to investigate HLA-DQB1 and HLA-DRB1 expression in IgAN patients and to explore the potential correlation between the expression of HLA-DQB1 and HLA-DRB1, and clinical pathological features. However, this study has several limitations. First, the study had a small sample size, which would have affected its statistical power. Second, information about treatments and follow-up data were not available. Thus, the long-term association between HLADQB1 and HLA-DRB1 expression and the prognosis of IgAN could not be examined. Future work will be needed to explore this association further.

In conclusion, our study found that the downregulation of HLA-DQB1 and HLA-DRB1 expression was positively correlated with clinical pathological features of IgAN, especially 24-h urinary protein excretion and the formation of crescents. Abnormal HLA-DQB1 and HLA-DRB1 expression might be involved in the development and progression of IgAN. The pathogenesis of IgAN requires further exploration.

\section{Acknowledgments}

Funding: This work was supported by a grant from the 
University of Electronic Science and Technology of China Central University Research Fund (ZYGX2019J104), the Science and Technology Project of Sichuan Province (2020YJ0447), the National Natural Science Foundation of China (81970641), the Sichuan Medical Research Project (S18040), the Science and Technology project of the heath planning Committee (19PJ132) and the Sichuan Clinical Research Center for Kidney Diseases (2019YFS0538). Dr. AYW is supported by the National Heart Foundation Post-Doctoral Fellowship and RACP jacquot Research Establishment Fellowship Australia.

\section{Footnote}

Reporting Checklist: The authors have completed the STROBE reporting checklist. Available at https://dx.doi. org/10.21037/apm-21-2065

Data Sharing Statement: Available at https://dx.doi. org/10.21037/apm-21-2065

Conflicts of Interest: All authors have completed the ICMJE uniform disclosure form (available at https://dx.doi. org/10.21037/apm-21-2065). All authors reported that this work was supported by a grant from the University of Electronic Science and Technology of China Central University Research Fund (ZYGX2019J104), the Science and Technology Project of Sichuan Province (2020YJ0447), the National Natural Science Foundation of China (81970641), the Sichuan Medical Research Project (S18040), the Science and Technology project of the heath planning Committee (19PJ132) and the Sichuan Clinical Research Center for Kidney Diseases (2019YFS0538). Dr. AYW is supported by the National Heart Foundation Post-Doctoral Fellowship and RACP jacquot Research Establishment Fellowship Australia. The other authors have no conflicts of interest to declare.

Ethical Statement: The authors are accountable for all aspects of the work in ensuring that questions related to the accuracy or integrity of any part of the work are appropriately investigated and resolved. The study protocol was approved by the ethics committee of Sichuan Provincial People's Hospital. All participants provided written informed consent prior to data collection. All procedures performed in this study involving human participants were in accordance with the Declaration of Helsinki (as revised in 2013).
Open Access Statement: This is an Open Access article distributed in accordance with the Creative Commons Attribution-NonCommercial-NoDerivs 4.0 International License (CC BY-NC-ND 4.0), which permits the noncommercial replication and distribution of the article with the strict proviso that no changes or edits are made and the original work is properly cited (including links to both the formal publication through the relevant DOI and the license). See: https://creativecommons.org/licenses/by-nc-nd/4.0/.

\section{References}

1. Berger J, Hinglais N. Intercapillary deposits of IgA-IgG. J Urol Nephrol (Paris) 1968;74:694-5.

2. Han $X$, Zheng $X$, Wang $Y$, et al. Random forest can accurately predict the development of end-stage renal disease in immunoglobulin a nephropathy patients. Ann Transl Med 2019;7:234.

3. Xu X, Wang G, Chen N, et al. Long-Term Exposure to Air Pollution and Increased Risk of Membranous Nephropathy in China. J Am Soc Nephrol 2016;27:3739-46.

4. Yu J, Ni X, Ni J, et al. Comparison of clinicopathological features and prognosis between IgA nephropathy and purpura nephritis in adults with diffuse endocapillary proliferation: a single-center cohort study. Ann Palliat Med 2020;9:795-804.

5. Hou JH, Zhu HX, Zhou ML, et al. Changes in the Spectrum of Kidney Diseases: An Analysis of 40,759 Biopsy-Proven Cases from 2003 to 2014 in China. Kidney Dis (Basel) 2018;4:10-9.

6. Robson KJ, Ooi JD, Holdsworth SR, et al. HLA and kidney disease: from associations to mechanisms. Nat Rev Nephrol 2018;14:636-55.

7. Feehally J, Farrall M, Boland A, et al. HLA has strongest association with IgA nephropathy in genome-wide analysis. J Am Soc Nephrol 2010;21:1791-7.

8. Yu XQ, Li M, Zhang H, et al. A genome-wide association study in Han Chinese identifies multiple susceptibility loci for IgA nephropathy. Nat Genet 2011;44:178-82.

9. Gharavi AG, Kiryluk K, Choi M, et al. Genome-wide association study identifies susceptibility loci for IgA nephropathy. Nat Genet 2011;43:321-7.

10. Kiryluk K, Li Y, Scolari F, et al. Discovery of new risk loci for IgA nephropathy implicates genes involved in immunity against intestinal pathogens. Nat Genet 2014;46:1187-96.

11. Wang W, Li M, Wang L, et al. DQB1*060101 may contribute to susceptibility to immunoglobulin A nephropathy in southern Han Chinese. Front Med 2016;10:507-16. 
12. Jiyun Y, Guisen L, Li Z, et al. The genetic variants at the HLA-DRB1 gene are associated with primary IgA nephropathy in Han Chinese. BMC Med Genet 2012;13:33.

13. Dendrou CA, Petersen J, Rossjohn J, et al. HLA variation and disease. Nat Rev Immunol 2018;18:325-39.

14. Le $W$, Liang $S, H u Y$, et al. Long-term renal survival and related risk factors in patients with $\mathrm{IgA}$ nephropathy: results from a cohort of 1155 cases in a Chinese adult population. Nephrol Dial Transplant 2012;27:1479-85.

15. Trimarchi H, Barratt J, Cattran DC, et al. Oxford Classification of IgA nephropathy 2016: an update from the IgA Nephropathy Classification Working Group. Kidney Int 2017;91:1014-21.

16. Yasutake J, Suzuki Y, Suzuki H, et al. Novel lectinindependent approach to detect galactose-deficient IgA1 in IgA nephropathy. Nephrol Dial Transplant 2015;30:1315-21.

17. Miller S, Tsou PS, Ciot P, et al. Hypomethylation of STAT1 and HLA-DRB1 is associated with type-I interferon-dependent HLA-DRB1 expression in lupus CD8+ T cells. Ann Rheum Dis 2019;78:519-28.

18. Kindt ASD, Fuerst RW, Knoop J, et al. Allele-specific methylation of type 1 diabetes susceptibility genes. J Autoimmun 2018;89:63-74.

19. Kular L, Liu Y, Ruhrmann S, et al. DNA methylation as a mediator of HLA-DRB1*15:01 and a protective variant in multiple sclerosis. Nat Commun 2018;9:2397.

20. O'Huigin C, Kulkarni S, Xu Y, et al. The molecular origin and consequences of escape from miRNA regulation by HLA-C alleles. Am J Hum Genet 2011;89:424-31.

21. Hofer TP, Frankenberger M, Heimbeck I, et al. Decreased expression of HLA-DQ and HLA-DR on cells of the monocytic lineage in cystic fibrosis. J Mol Med (Berl) 2014;92:1293-304.

22. Moldoveanu Z, Wyatt RJ, Lee JY, et al. Patients with IgA nephropathy have increased serum galactose-deficient IgA1 levels. Kidney Int 2007;71:1148-54.

23. Pattrapornpisut P, Avila-Casado C, Reich HN. IgA Nephropathy: Core Curriculum 2021. Am J Kidney Dis

Cite this article as: Zhan X, Deng F, Wang AY, Chen Q, Du Y, Wang Q, Zhong X, Zhang P, Wang W, Chen S, Li G, Wang L, Wang W. HLA-DQB1 and HLA-DRB1 expression is associated with disease severity in IgAN. Ann Palliat Med 2021;10(9):94539466. doi: 10.21037/apm-21-2065
2021;78:429-41.

24. Bariety J, Bruneval P, Hill G, et al. Posttransplantation relapse of FSGS is characterized by glomerular epithelial cell transdifferentiation. J Am Soc Nephrol 2001;12:261-74.

25. Wen J, Xie K, Zhang M, et al. HLA-DR, and not PLA2R, is expressed on the podocytes in kidney allografts in de novo membranous nephropathy. Medicine (Baltimore) 2016;95:e4809.

26. Cravedi P, Remuzzi G. Pathophysiology of proteinuria and its value as an outcome measure in chronic kidney disease. Br J Clin Pharmacol 2013;76:516-23.

27. Westhorpe CLV, Norman MU, Hall P, et al. Effector CD4 $T$ cells recognize intravascular antigen presented by patrolling monocytes. Nat Commun 2018;9:747.

28. Lion J, Taflin C, Cross AR, et al. HLA Class II Antibody Activation of Endothelial Cells Promotes Th17 and Disrupts Regulatory T Lymphocyte Expansion. Am J Transplant 2016;16:1408-20.

29. Summers SA, Steinmetz OM, Li M, et al. Th1 and Th17 cells induce proliferative glomerulonephritis. J Am Soc Nephrol 2009;20:2518-24.

30. Kuo HL, Huang CC, Lin TY, et al. IL-17 and CD40 ligand synergistically stimulate the chronicity of diabetic nephropathy. Nephrol Dial Transplant 2018;33:248-56.

31. Hunemorder S, Treder J, Ahrens S, et al. TH1 and TH17 cells promote crescent formation in experimental autoimmune glomerulonephritis. J Pathol 2015;237:62-71.

32. Kitching AR, Holdsworth SR, Tipping PG. IFN-gamma mediates crescent formation and cell-mediated immune injury in murine glomerulonephritis. J Am Soc Nephrol 1999;10:752-9.

33. Paust HJ, Ostmann A, Erhardt A, et al. Regulatory T cells control the Th1 immune response in murine crescentic glomerulonephritis. Kidney Int 2011;80:154-64.

34. Paust HJ, Riedel JH, Krebs CF, et al. CXCR3+ Regulatory T Cells Control TH1 Responses in Crescentic GN. J Am Soc Nephrol 2016;27:1933-42. 


\section{Supplementary}

Table S1 Differential expression of HLA-DQB1 protein between IgAN patients and healthy control patients

\begin{tabular}{|c|c|c|c|}
\hline & $\lg A N$ & Control & $\mathrm{P}$ \\
\hline Nucleated cell & $665.00(559.00,886.00)$ & $790.00(598.00,1,042.00)$ & $0.04^{*}$ \\
\hline Lymphocyte & $1,195.00(806.00,1,550.00)$ & $1,396.00(1,030.00,2,108.00)$ & 0.10 \\
\hline T cell & $246.00(197.00,298.00)$ & $246.00(204.00,317.00)$ & 0.46 \\
\hline NK cell & $363.00(260.00,529.00)$ & $593.00(430.00,919.00)$ & $<0.001^{\star \star *}$ \\
\hline Monocyte & $1,458.00(983.00,2,576.00)$ & $1,416.00(931.00,1,930.00)$ & 0.27 \\
\hline Granulocyte & $332.00(299.00,396.00)$ & $387.00(361.00,408.00)$ & $0.01^{*}$ \\
\hline
\end{tabular}

${ }^{*} \mathrm{P}<0.05 ;{ }^{* *} \mathrm{P}<0.01 ;{ }^{* \star *} \mathrm{P}<0.001$

Table S2 Differential expression of HLA-DRB1 protein between IgAN patients and healthy control patients

\begin{tabular}{|c|c|c|c|}
\hline & $\lg A N$ & Control & $\mathrm{P}$ \\
\hline Nucleated cell & $800.00(559.00,1,143.00)$ & $878.00(598.00,1,081.00)$ & 0.88 \\
\hline Lymphocyte & $1,601.00(1,009.00,2,204.00)$ & $1,510.00(1,124.00,2,190.00)$ & 0.88 \\
\hline T cell & $193.00(109.00,313.00)$ & $192.00(98.00,316.00)$ & 0.65 \\
\hline NK cell & $331.00(102.00,584.00)$ & $532.00(257.00,904.00)$ & $<0.01^{\star \star}$ \\
\hline Monocyte & $3,849.00(2,785.00,6,522.00)$ & $3,720.00(2,238.00,4,930.00)$ & 0.24 \\
\hline Granulocyte & $191.00(172.00,222.00)$ & $168.00(155.00,183.00)$ & $<0.001^{\star \star \star}$ \\
\hline
\end{tabular}

${ }^{\star \star} \mathrm{P}<0.01 ;{ }^{\star \star *} \mathrm{P}<0.001$. 
Table S3 Correlation between HLA-DQB1 and HLA-DRB1 mRNA and clinical characteristics

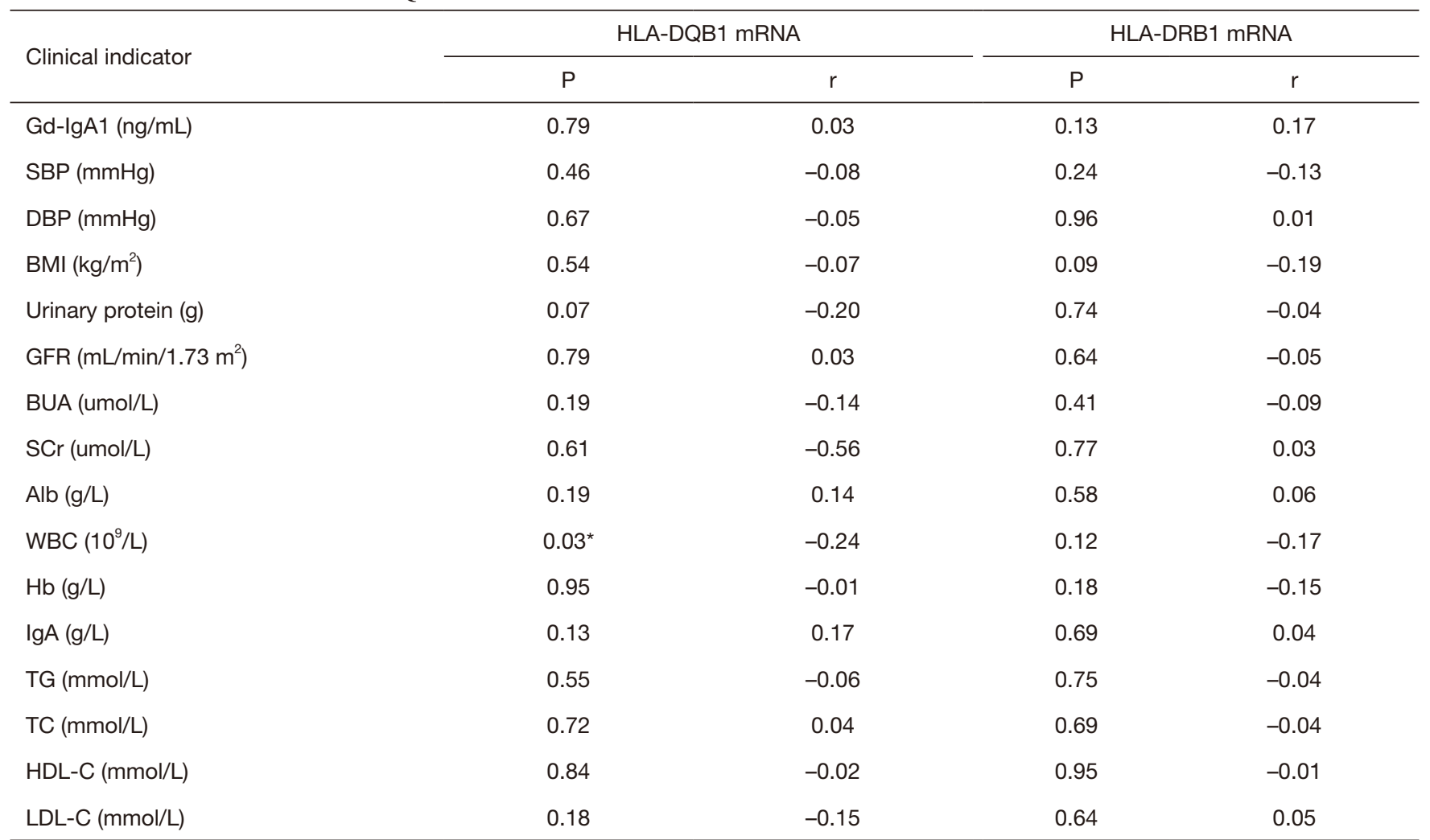

Gd-IgA1, galactose-deficient IgA1; SBP, systolic blood pressure; DBP, diastolic blood pressure; BMI, body mass index; 24-h urinary protein, 24 hour urinary protein; eGFR, estimated glomerular filtration rate; UA, uric acid; SCr, serum creatinine; Alb, serum albumin; WBC, white blood cells; Hb, hemoglobin; TC, total cholesterol; TG, triglyceride; LDL-C, low density lipoprotein cholesterol; HDL-C; high density lipoprotein cholesterol; ${ }^{*} \mathrm{P}<0.05$. 
Table S4 Differential expression of HLA-DQB1 and HLA-DRB1 mRNA in different clinical pathological groups

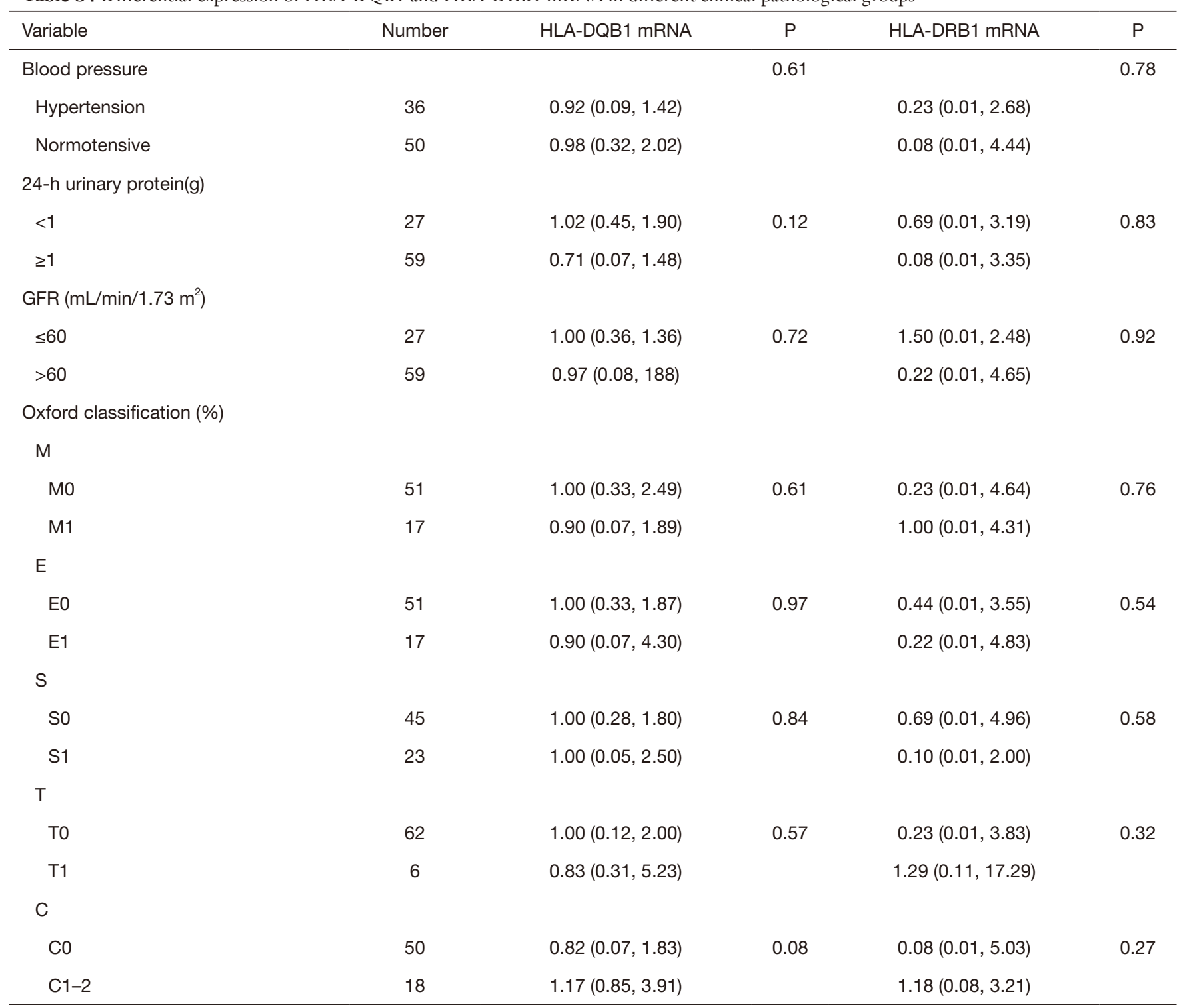

eGFR, estimated glomerular filtration rate; M, mesangial cell proliferation; E, endothelial cell proliferation; S, glomerular segmental sclerosis; T, tubular atrophy, interstitial fibrosis; C, crescentic lesion. 
Table S5 Expression of HLA-DQB1 and HLA-DRB1 protein between high and low urinary protein excretion groups

\begin{tabular}{|c|c|c|c|}
\hline & 24-h urinary protein $<1 \mathrm{~g}$ & 24-h urinary protein $\geq 1 \mathrm{~g}$ & $\mathrm{P}$ \\
\hline DQB1-nucleated cell & $661.00(570.00,1,065.00)$ & $665.00(538.00,842.00)$ & 0.66 \\
\hline DQB1-lymphocyte & $1,195.00(806.00,2,458.00)$ & $1,170.00(787.00,1,391.00)$ & 0.38 \\
\hline DQB1-T cell & $238.00(183.00,319.00)$ & $248.00(213.00,298.00)$ & 0.61 \\
\hline DQB1-NK cell & $276.00(211.00,452.00)$ & $373.00(296.00,676.00)$ & 0.05 \\
\hline DQB1-monocyte & $1,566.00(981.00,2,574.00)$ & $1,456.00(1,055.00,2,641.00)$ & 0.99 \\
\hline DQB1-granulocyte & $316.00(283.00,360.00)$ & $352.00(317.00,429.00)$ & $<0.01^{\star \star}$ \\
\hline DRB1-nucleated cell & $837.00(458.00,1166.00)$ & $799.00(662.00,1,143.00)$ & 0.67 \\
\hline DRB1-B cell & $9,098.00(5,458.00,13,545.00)$ & $10,526.00(7,686.00,19,152.00)$ & 0.21 \\
\hline DRB1-NK cell & $171.00(61.00,438.00)$ & $415.00(118.00,803.00)$ & $0.02^{*}$ \\
\hline DRB1-monocyte & $3,849.00(2,417.00,4,705.00)$ & $3,852.00(3,143.00,7,490.00)$ & 0.36 \\
\hline DRB1-granulocyte & $191.00(162.00,219.00)$ & $190.00(172.00,230.00)$ & 0.66 \\
\hline
\end{tabular}

${ }^{*} \mathrm{P}<0.05 ;{ }^{* \star} \mathrm{P}<0.01$. 
Table S6 Expression of HLA-DQB1 and HLA-DRB1 protein between hypertensive and normotensive groups

\begin{tabular}{|c|c|c|c|}
\hline & Normal blood pressure & Hypertension & $\mathrm{p}$ \\
\hline DQB1-nucleated cell & $633.00(564.50,831.50)$ & $715.50(537.00,955.00)$ & 0.44 \\
\hline DQB1-lymphocyte & $1,106.00(785.50,1,418.00)$ & $1,252.00(1,045.50,2,057.50)$ & 0.28 \\
\hline DQB1-T cell & $237.00(191.00,264.00)$ & $271.50(201.50,356.75)$ & 0.15 \\
\hline DQB1-NK cell & $338.00(263.50,486.00)$ & $450.00(244.75,684.25)$ & 0.35 \\
\hline DQB1-monocyte & $1,458.00(1,176.00,2,339.50)$ & $1,474.00(910.00,2,746.50)$ & 0.74 \\
\hline DQB1-granulocyte & $334.00(305.50,394.00)$ & $325.50(297.50,426.00)$ & 0.88 \\
\hline DRB1-nucleated cell & $875.00(687.00,1,252.00)$ & $724.00(506.75,906.25)$ & 0.09 \\
\hline DRB1-B cell & $11,100.00(7,289.00,17,460.50)$ & $8,316.00(6,679.25,13,008.00)$ & 0.21 \\
\hline DRB1-NK cell & $344.00(101.00,529.00)$ & $322.00(105.50,699.50)$ & 0.86 \\
\hline DRB1-monocyte & $4,313.00(3,401.50,6,919.50)$ & $3,278.00(2,353.50,4,358.00)$ & 0.07 \\
\hline DRB1-granulocyte & $198.00(175.00,234.50)$ & $188.00(160.50,220.50)$ & 0.59 \\
\hline
\end{tabular}

Table S7 Expression of HLA-DQB1 and HLA-DRB1 protein between low and high eGFR groups

\begin{tabular}{|c|c|c|c|}
\hline & eGFR $\leq 60 \mathrm{~mL} / \mathrm{min} / 1.73 \mathrm{~mm}^{2}$ & eGFR $>60 \mathrm{~mL} / \mathrm{min} / 1.73 \mathrm{~mm}^{2}$ & $\mathrm{P}$ \\
\hline DQB1-nucleated cell & $667.50(479.50,760.75)$ & $663.00(570.00,964.00)$ & 0.29 \\
\hline DQB1-lymphocyte & $1,077.50(781.50,1,311.75)$ & $1,315.00(806.00,1,739.00)$ & 0.17 \\
\hline DQB1-T cell & $255.50(218.00,350.25)$ & $231.00(183.00,283.00)$ & 0.13 \\
\hline DQB1-NK cell & $357.50(253.25,656.25)$ & $363.00(267.00,525.00)$ & 0.89 \\
\hline DQB1-monocyte & $1,421.00(937.00,2,525.75)$ & $1,505.00(1,055.00,2,576.00)$ & 0.46 \\
\hline DQB1-granulocyte & $343.00(314.75,393.75)$ & $332.00(298.00,429.00)$ & 0.93 \\
\hline DRB1-nucleated cell & $784.50(444.25,947.25)$ & $818.00(662.00,1,200.00)$ & 0.24 \\
\hline DRB1-B cell & $9,791.50(5,821.25,15,945.00)$ & $10,526.00(7,331.00,16,466.00)$ & 0.59 \\
\hline DRB1-NK cell & $223.00(128.25,551.00)$ & $369.00(80.00,663.00)$ & 0.87 \\
\hline DRB1-monocyte & $3,731.50(1,859.00,6,068.75)$ & $3,849.00(2918.00,6,613.00)$ & 0.54 \\
\hline DRB1-granulocyte & $187.00(163.50,227.50)$ & $198.00(178.00,222.00)$ & 0.49 \\
\hline
\end{tabular}

eGFR, estimated glomerular filtration rate. 
Table S8 Differential expression of HLA-DQB1 and HLA-DRB1 protein in M0 and M1 groups

\begin{tabular}{|c|c|c|c|}
\hline & MO & M1 & $\mathrm{P}$ \\
\hline DQB1-nucleated cell & $664.00(580.50,930.75)$ & $788.00(478.25,904.75)$ & 0.91 \\
\hline DQB1-lymphocyte & $1,200.00(836.00,1,700.00)$ & $1,138.00(981.50,1,458.00)$ & 0.89 \\
\hline DQB1-T cell & $234.00(196.00,320.75)$ & $229.50(183.75,264.25)$ & 0.57 \\
\hline DQB1-NK cell & $326.00(229.75,497.00)$ & $357.50(312.50,629.50)$ & 0.26 \\
\hline DQB1-monocyte & $1,451.50(1037.00,2,423.25)$ & $1,656.00(831.75,2,474.25)$ & 0.84 \\
\hline DQB1-granulocyte & $332.00(308.75,402.50)$ & $372.50(294.50,433.50)$ & 0.72 \\
\hline DRB1-nucleated cell & $802.00(521.75,1,174.50)$ & $784.50(673.50,899.25)$ & 0.77 \\
\hline DRB1-B cell & $9,346.00(5,727.75,14,826.50)$ & $10,147.00(8,057.25,11,557.00)$ & 0.96 \\
\hline DRB1-NK cell & $203.00(73.25,513.50)$ & $410.50(336.25,524.75)$ & 0.07 \\
\hline DRB1-monocyte & $3,700.50(2528.75,6,544.75)$ & $3,907.00(3,326.00,6,341.25)$ & 0.49 \\
\hline DRB1-granulocyte & $188.00(176.50,219.00)$ & $210.50(174.00,227.00)$ & 0.53 \\
\hline
\end{tabular}

M0, mesangial cell proliferation score $<0.5$; M1, mesangial cell proliferation score $>0.5$.

Table S9 Differential expression of HLA-DQB1 and HLA-DRB1 protein in E0 and E1 groups

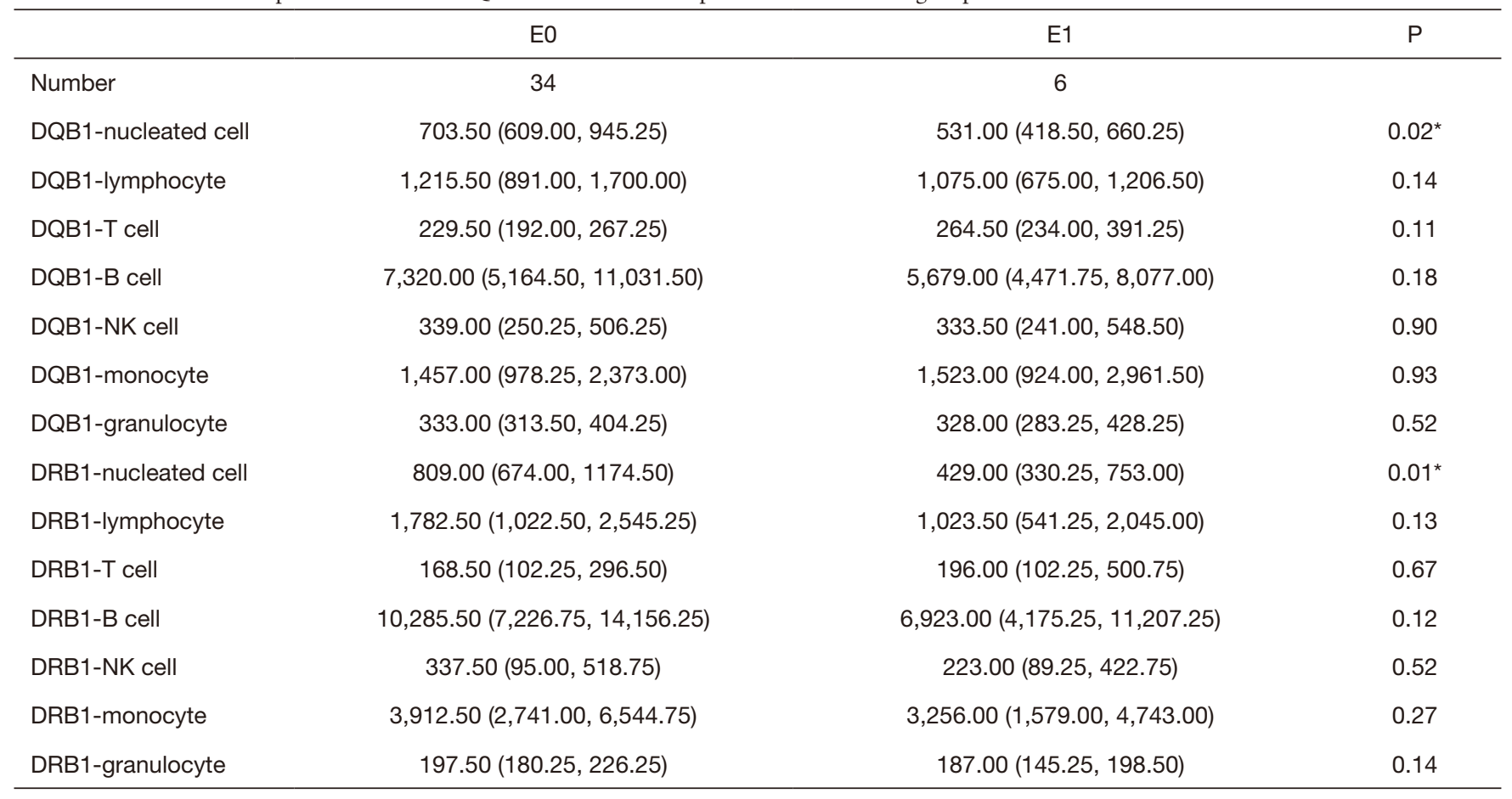

E0, endocapillary hypercellularity absent; E1, endocapillary hypercellularity present; ${ }^{\star} \mathrm{P}<0.05$. 
Table S10 Differential expression of HLA-DQB1 and HLA-DRB1 protein in S0 and S1 groups

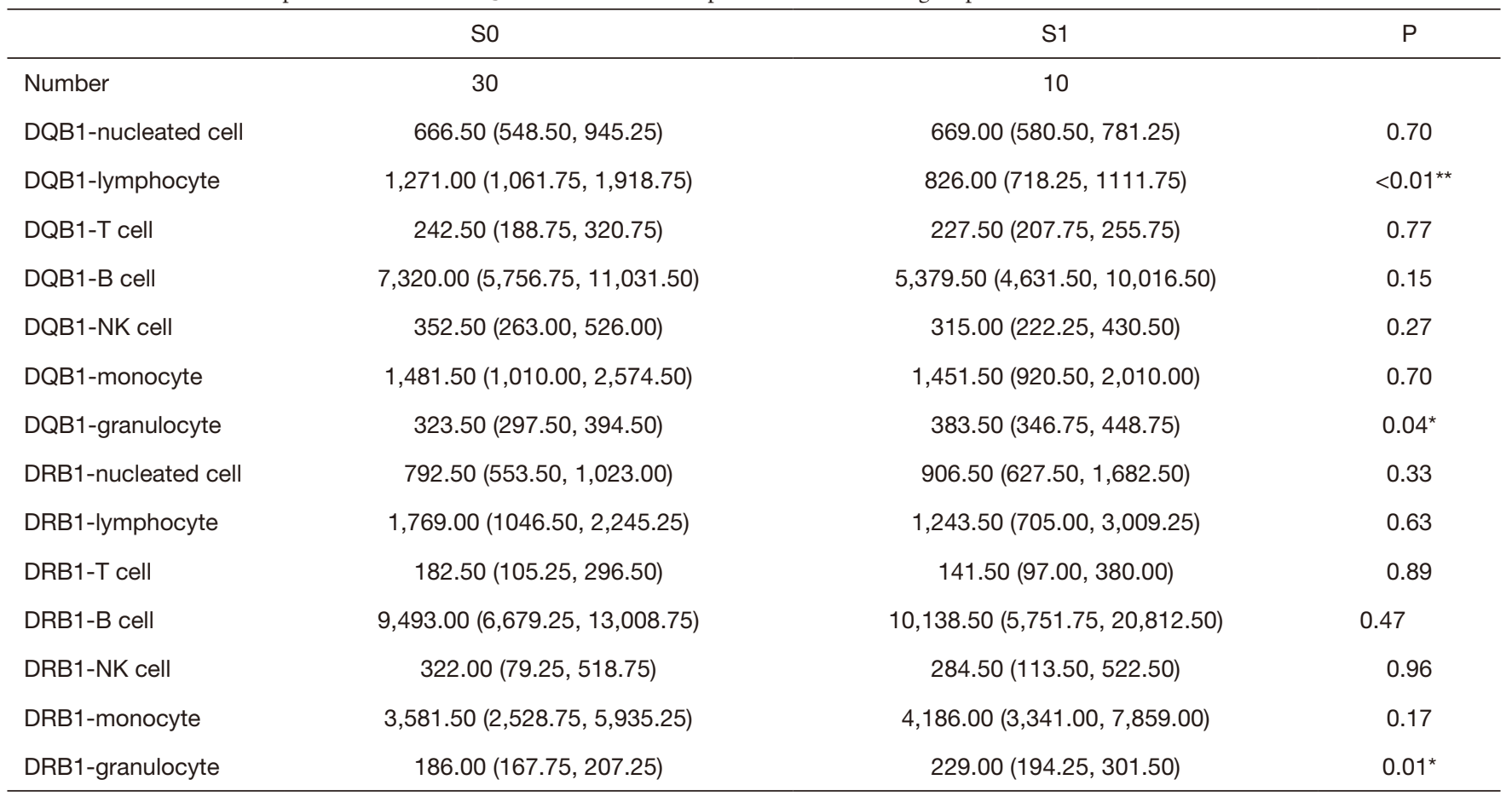

S0, segmental glomerulosclerosis absent; $\mathrm{S} 1$, segmental glomerulosclerosis present. ${ }^{\star} \mathrm{P}<0.05 ;{ }^{*} \mathrm{P}<0.01$.

Table S11 Differential expression of HLA-DQB1 and HLA-DRB1 protein in C0 and C1-2 groups

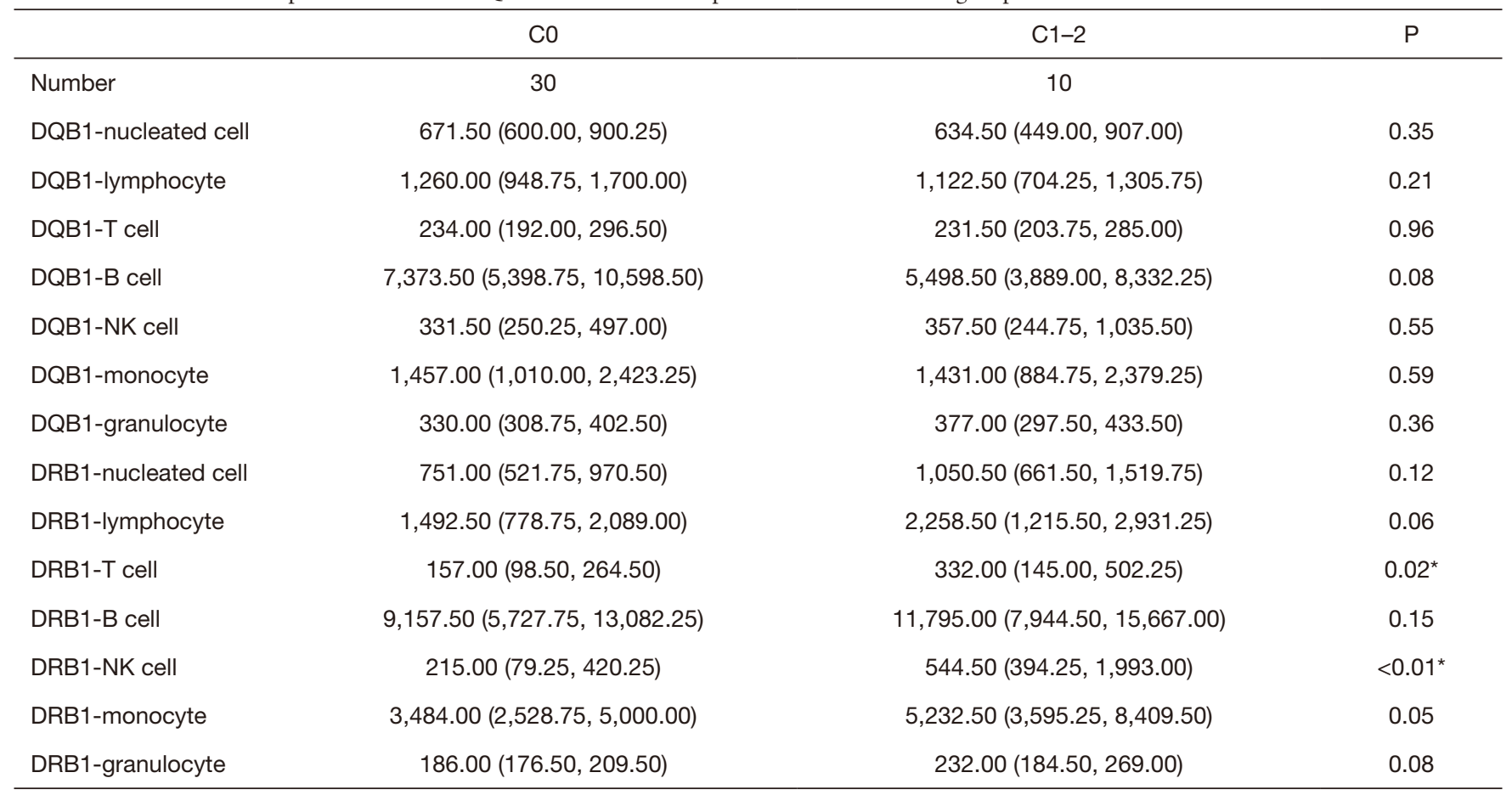

$\mathrm{C0}$, cellular/fibro-cellular crescents absent; $\mathrm{C} 1-2$, cellular/fibro-cellular crescents present. ${ }^{*} \mathrm{P}<0.05$. 